\title{
Identification of the Roles of Climate Factors, Engineering Construction, and Agricultural Practices in Vegetation Dynamics in the Lhasa River Basin, Tibetan Plateau
}

\author{
Dan $\mathrm{Li}^{1}$, Hongying Luo ${ }^{2}$, Tiesong $\mathrm{Hu}^{1}$, Dongguo Shao ${ }^{1}$, Yuanlai Cui ${ }^{1}$, Shahbaz Khan ${ }^{1,3}$ and \\ Yufeng Luo ${ }^{1,2, *}$ \\ 1 State Key Laboratory of Water Resources and Hydropower Engineering Science, Wuhan University, \\ Wuhan 430072, China; lidann@whu.edu.cn (D.L.); tshu@whu.edu.cn (T.H.); dgshao@whu.edu.cn (D.S.); \\ YLCui@whu.edu.cn (Y.C.); s.khan@unesco.org (S.K.) \\ 2 School of Water Resources and Civil Engineering, Tibet Agricultural and Animal Husbandry College, \\ Nyingchi 860000, China; lhy@xza.edu.cn \\ 3 Regional Science Bureau for Asia and the Pacific, the United Nations Educational, Scientific and Cultural \\ Organization, DKI Jakarta 12110, Indonesia \\ * Correspondence: yfluo@whu.edu.cn
}

Received: 19 April 2020; Accepted: 8 June 2020; Published: 10 June 2020

\begin{abstract}
Understanding vegetation dynamics is necessary to address potential ecological threats and develop sustainable ecosystem management at high altitudes. In this study, we revealed the spatiotemporal characteristics of vegetation growth in the Lhasa River Basin using net primary productivity (NPP) and normalized difference vegetation index (NDVI) during the period of 2000-2005. The roles of climatic factors and specific anthropogenic activities in vegetation dynamics were also identified, including positive or negative effects and the degree of impact. The results indicated that the interannual series of NPP and NDVI in the whole basin both had a continuous increasing trend from 102 to $128 \mathrm{gC} \mathrm{m}^{-2} \mathrm{yr}^{-1}$ and from 0.417 to $0.489(p<0.05)$, respectively. The strongest advanced trends ( $>2 \mathrm{gC} \mathrm{m}^{-2} \mathrm{yr}^{-1}$ or $>0.005 \mathrm{yr}^{-1}$ ) were detected in mainly the southeastern and northeastern regions. Vegetation dynamics were not detected in $10 \%$ of the basin. Only $20 \%$ of vegetation dynamics were driven by climatic conditions, and precipitation was the controlling climatic factor determining vegetation growth. Accordingly, anthropogenic activities made a great difference in vegetation coverage, accounting for about $70 \%$. The construction of urbanization and reservoir led to vegetation degradation, but the farmland practices contributed the vegetation growth. Reservoir construction had an adverse impact on vegetation within $6 \mathrm{~km}$ of the river, and the direct damage to vegetation was within $1 \mathrm{~km}$. The impacts of urbanization were more serious than that of reservoir construction. Urban sprawl had an adverse impact on vegetation within a $6 \mathrm{~km}$ distance from the surrounding river and resulted in the degradation of vegetation, especially within a $3 \mathrm{~km}$ range. Intensive fertilization and guaranteed irrigation improved the cropland ecosystem conditions, creating a favorable effect on the accumulation of crop organic matter in a range of $5 \mathrm{~km}$, with an NPP trend value of $1.2 \mathrm{gC} \mathrm{m}^{-2} \mathrm{yr}^{-1}$. The highly intensive grazing activity forced ecological environmental pressures such that the correlation between livestock numbers and vegetation growth trend was significantly linear negative.
\end{abstract}

Keywords: vegetation dynamics; climatic factor; urbanization; reservoir construction; agriculture practices; degree of impact 


\section{Introduction}

Vegetation has been considered a vital medium in characterizing and clarifying the surface energy exchange, biogeochemical cycle, and water cycle in global terrestrial ecosystems $[1,2]$. Vegetation dynamics, as a long-term and complex process, are involved in regulating the carbon balance and reducing greenhouse gas emissions, as well as directly influencing climate and ecosystem stability [3,4]. Terrestrial ecosystems are easily subject to a combination of climate factors and human disturbances $[5,6]$. The ecosystem services provided by vegetation are easily disturbed by environmental and management changes such as climate change, land conversions, and agriculture practices [7-9]. Under the background of global warming and the requirement of sustainable development, improving our ability to specifically interpret the vegetation response to climatic and anthropogenic factors contributes to formulating countermeasures and management policies from a regional or national perspective.

The value of satellite imagery as the major means for monitoring vegetation growth at large scales has long been recognized [10-12]. The net primary productivity (NPP) and the normalized difference vegetation index (NDVI) are two key indicators adopted for understanding vegetation accumulated organic matter and green vegetation coverage, which have been widely employed in the field of variability in vegetation at both local and global scales [13-15]. In past decades, numerous issues concerning the mutual relationships between vegetation and climatic variables have been addressed $[16,17]$. Numerous studies have confirmed that the responses of vegetation dynamics to climatic variables are characterized by spatial non-stationarity and temporal heterogeneity $[18,19]$. However, few studies have been carried out at the watershed scale, especially in southwest rivers. Several efforts have also been devoted to quantifying the damage of human activities to vegetation dynamics within a specific region [20-22]. However, these studies either generally illustrated these effects from the perspective of land use and cover change $[23,24]$ or distinguished the contribution of human activities based on mathematical formulas such as regression analyses [25,26], which is not able to take total anthropogenic factors and their complex interactions in consideration. In fact, anthropogenic activities (e.g., population, afforestation area, urbanization, grazing) can be very complicated and diverse. Limited attempts have been made to systematically explore the effect of human activities on the vegetation dynamics within a specific region, where there may be more than one human activity. Problems such as the specific types of human activities and their range of positive or negative effects have not been solved.

The Tibetan Plateau (TP) is an important ecological barrier area where the ecosystem is extremely vulnerable. Therefore, the plateau ecosystem is susceptible to an artificial disturbance $[27,28]$. Despite the large area of the plateau, the population is mainly distributed in narrow river valleys, leading to a great intensity of human activities. The Lhasa River Basin is the most densely populated area on the $\mathrm{TP}$, where the ecosystem service is closely related to the well-being of residents in the lower reaches and sustainable development of the basin and even the whole TP [29,30]. During the "eighth five-year plan" period, state and local governments proposed the comprehensive development project in Lhasa River Basin to promote agriculture and animal husbandry and accelerate economic development. Thus, the Lhasa River Basin has undergone dramatic changes in recent decades, including urbanization driven by increasing populations, the construction of large water conservancy projects, and intensive agriculture practices to ensure production security. These policies orientations attracted wide attention from society. Urbanization can alter the ecosystem composition and structure due to land conversions and consequently has a significant effect on ecosystem processes and functioning [31]. The impoundment of reservoirs may lead to the expansion of non-vegetation coverage in the upstream, and the reservoir reconstruction is responsible for decrease in grasslands [11,32]. Intensified agricultural management, such as prevailing irrigation and application of chemical fertilizers, has shifted the vegetation productivity process $[9,33]$. The overexploitation of the grassland, which is induced by increasing grazing pressure, led to soil structural decline and further triggered land degradation [34]. The "one river and two tributaries" project was completed in 2000, and climate change has worsened 
in the 21st century. Huang et al. (2016) confirmed the year 2000 as the year of significant climate change point in Tibet. The responses of vegetation dynamics to climatic conditions and anthropogenic activities from a watershed ecology perspective remain poorly understood [35].

The objective of this study is to investigate the spatial-temporal change patterns of vegetation growth, as well as examine the mechanisms of NPP and NDVI responses to climatic factors and human activities in the Lhasa River Basin during the period of 2000-2005. The purposes are (1) to analyze the spatiotemporal dynamics of NPP and NDVI in recent decades, (2) to partition the vegetation dynamics driven by climatic factors, and (3) to quantify the relationship between human-induced factors and vegetation dynamics, and determine the range of influence. Our findings contribute to making clear the driving factors of vegetation dynamics and provide important information for regional ecological environment protection.

\section{Materials and Methods}

\subsection{Study Area}

The Lhasa River Basin, which is located in the southwest of the TP, is the largest and most important tributary of the Yarlung Zangbo River, with a total area of $32,588 \mathrm{~km}^{2}$. The geographical coordinates are $90^{\circ} 05^{\prime} \mathrm{E}-93^{\circ} 20^{\prime} \mathrm{E}, 29^{\circ} 20^{\prime} \mathrm{N}-31^{\circ} 15^{\prime} \mathrm{N}$. High mountains and deep gorges are distributed as a mosaic with a slight slope from northeast (over $7000 \mathrm{~m}$ ) to southwest (below $3700 \mathrm{~m}$ ), which has high landscape heterogeneity. In this study area, the plateau temperate semiarid monsoon climate is subjected to an annual average temperature of $7.7^{\circ} \mathrm{C}$ due to the high altitude and a mean annual precipitation of $440 \mathrm{~mm}$. The precipitation is unevenly distributed throughout the year, with $80 \%$ of the yearly total in summer and autumn.

Human activities are concentrated in the lower valley below $4500 \mathrm{~m}$. In response to the national policy for development in the One River and Two Tributaries region of Tibet, since 2000, the government has made great efforts to construct water conservancy facilities and irrigated districts and accelerate urbanization to improve the living standards of local people. The Zhikong Reservoir (completed in 2006) and Pangduo Reservoir (completed in 2013) formed the cascade structure of hydropower in the midstream of the Lhasa River (Figure 1a). In mountainous regions, urbanization and reservoir construction often bring about large-scale physical disturbances, including cut and fill operations that destroy grasslands and croplands. Additionally, the Moda irrigated district and Pengbo irrigated district were vigorously developed to ensure local grain yield. The Moda irrigated district is distributed along the main stream of the Lhasa River, while Pengbo irrigated district is located on both banks of the Pengbo River (a tributary of Lhasa River) (Figure 1b). The main crops are highland barley, winter wheat, and potatoes. The population of the Lhasa River Basin is mainly concentrated in the urban areas of the lower river valley, and there are few people in the upper mountain meadow and forest area (Figure 1c). Temperate steppe is the dominant ecosystem type above $4500 \mathrm{~m}$, occupying nearly $70 \%$ of the whole basin, where sheep and yak pastures are the most common anthropogenic activities, while the forest area would show little human disturbance due to few populations and no grazing. 

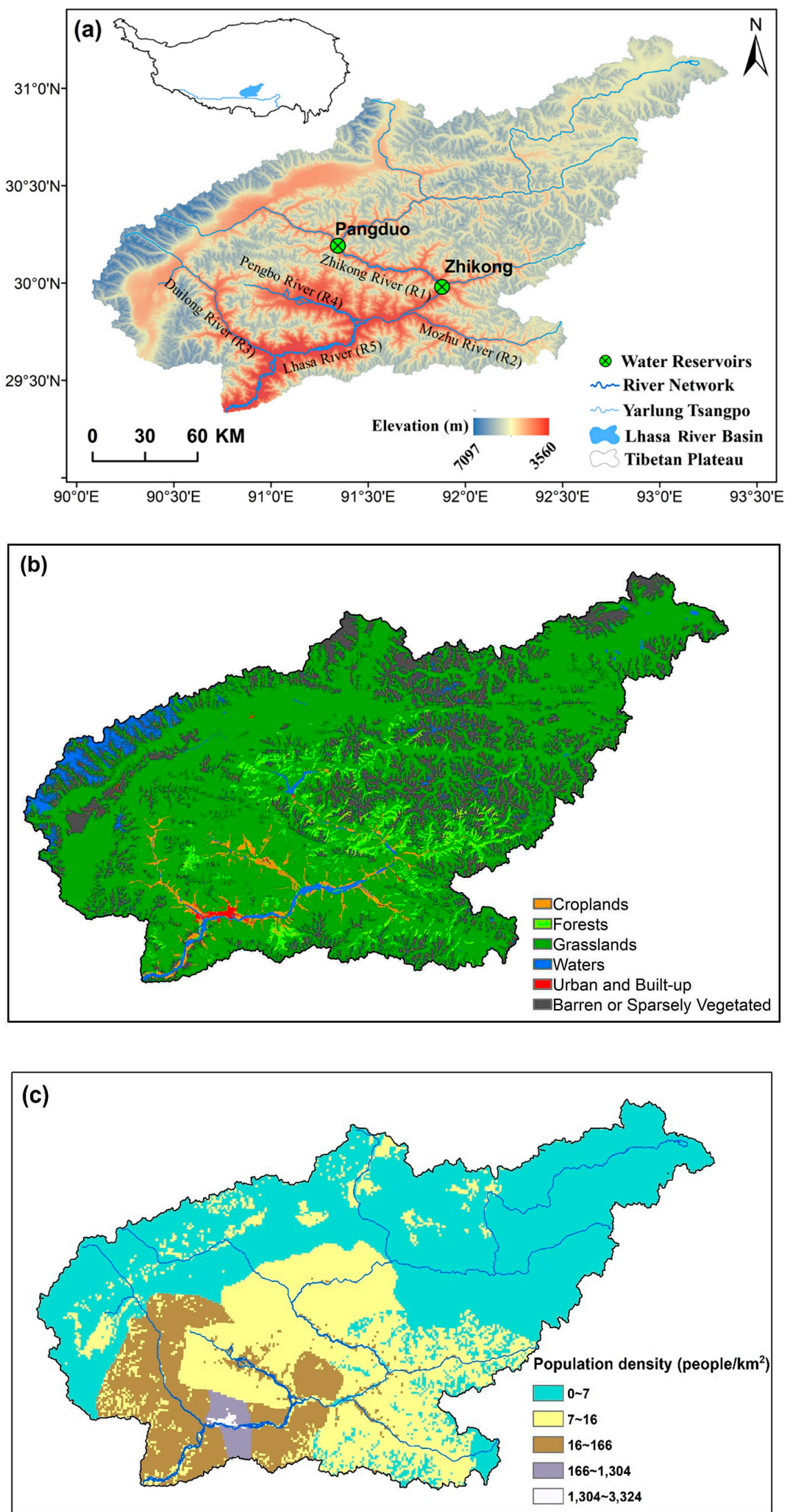

Figure 1. The study area: (a) location of the Lhasa River Basin; (b) the land cover map; and (c) spatial distribution of people density in 2015. 


\subsection{Data Source}

The annual NPP datasets in 2000-2005at a $1 \mathrm{~km} \times 1 \mathrm{~km}$ spatial resolution were retrieved from the global MOD17A3 products of the NASA Earth Observation System (EOS) program and processed by the Numerical Terra Dynamic Simulation Group (NTSG) (http://www.ntsg.umt.edu/project/modis/mod17). The MOD17 algorithm typically adopted the light-use efficiency model, and validation efforts were made by using the spatially nonlinear interpolation of the input Global Modeling and Assimilation Office (GMAO) meteorology, a linear temporal gap-filling technique of leaf area index (LAI) and absorbed photosynthetically active radiation (FPAR) and recalibrated Biome Properties Lookup Table (BPLUT); for more details, see Running et al. (2004) [36] and Zhao et al. (2005) [37]. The MOD17 was able to capture the spatiotemporal variation in NPP under different biomes and climate regimes, and no consistent overestimation or underestimation was found compared with the field NPP observations [38]. The MOD17A3 products have popularity in previous studies of carbon exchange and ecosystem productivity at regional and global scales [39-41].

The global 16-day MODIS NDVI products (MOD13A2) with a $1 \mathrm{~km} \times 1 \mathrm{~km}$ spatial resolution were used in this study (available at https://ladsweb.modaps.eosdis.nasa.gov/). The MOD13A2 data were generated from atmospherically corrected bidirectional surface reflectance that had been masked for water, clouds, heavy aerosols, and cloud shadows [42]. A wide range of distribution locations and ground-truth and validation efforts during the periods were adopted for the evaluation of accuracy. These data could be used for characterizing land surface biophysical properties and processes. To reduce the negative impacts of cloud contamination and atmospheric variability, the maximum value composite (MVC) method was applied to pick the higher value for each pixel of two-period images to obtain the monthly NDVI. Then, the annual NDVI values were calculated for every year from 2000 to 2015. Only the pixels where the multiyear average NDVI was higher than 0.2 in the basin were selected to eliminate the disturbance of barren and no vegetated signals [43]. The annual precipitation and temperature records at a $1 \mathrm{~km} \times 1 \mathrm{~km}$ spatial resolution were obtained from the Data Center for Resources and Environmental Sciences, Chinese Academy of Sciences (RESDC) (http://www.resdc.cn). The national 2400 station-based observational data from the National Meteorological Information Center (NMIC) of the China Meteorological Administration were interpolated using thin-plated smoothing splines (ANUSPLIN) to produce continuous raster images. Both NDVI data and meteorological data were resampled and re-projected to ensure the spatial consistency with NPP data. The socioeconomic data at a county resolution from 2000 to 2015, including the livestock type, herd number data, irrigated area, and the amount of fertilizers and pesticides, were acquired from the Tibet Statistical Yearbooks. The herd number data were converted into the unit of a standard sheep to quantify the stocking intensity for 7 counties. Specifically, 1 head of large livestock (yaks and horses) is equivalent to 5 sheep units.

\subsection{Statistical Analysis}

The linear trend analysis on a per-pixel basis was used to identify the trends under the long time series in the NPP and NDVI variables:

$$
\text { slope }=\frac{n \times \sum_{i=1}^{n} i \times X_{i}-\sum_{i=1}^{n} i \sum_{i=1}^{n} X_{i}}{n \times \sum_{i=1}^{n} i^{2}-\left(\sum_{i=1}^{n} i\right)^{2}}
$$

where $X_{i}$ indicates the time-series variable, and $i$ is the sample sequence number, $t=1,2, \ldots, n$, where $n$ is the number of time periods. A slope value greater than zero indicates an upward trend of the corresponding variable, while a slope value less than zero means a downward trend. The absolute value of the slope represents the magnitude of change. 
Pixel-based partial correlation coefficients between NPP or NDVI and precipitation and temperature were calculated as follows:

$$
r_{x y, z}=\frac{r_{x y}-r_{x z} r_{y z}}{\sqrt{\left(1-r_{x z}^{2}\right)\left(1-r_{y z}^{2}\right)}}
$$

where $r_{x y}$ is the Pearson correlation coefficient. $r_{x y, z}$ describes the relationship between the $x$ variable and the $y$ variable with the effect of the $z$ variable removed. A $t$-test was used to examine the significance of the correlations at a significance level of 0.05 .

Considering the interaction between the meteorological factors, the multiple correlation coefficient was used to describe the combined effects of precipitation and temperature on NPP or NDVI at a significance level of 0.05 by the $F$-test:

$$
r_{x, y z}=\sqrt{1-\left(1-r_{x y}^{2}\right)\left(1-r_{x z, y}^{2}\right)}
$$

The zoning criteria were adopted for identifying the driving factors of vegetation dynamics (climatic and non-climatic) based on the partial correlation coefficient and multiple correlation coefficient analysis. We identified the areas where no vegetation dynamics occurred (the change trend of NPP or NDVI equal to zero) as no change zone (NOC), and then determined the driving factors of vegetation dynamics in the remaining pixels. Pixels meeting the significant multiple correlation and partial correlation between NPP (NDVI) and precipitation were defined as precipitation driven type (P); pixels meeting the significant multiple correlation and partial correlation between NPP (NDVI) and temperature were defined as temperature-driven type (T); and pixels meeting the significant multiple correlation and simultaneously meeting the significant or nonsignificant partial correlation were defined as precipitation and temperature driven type (PT). Those that did not meet the significant multiple correlation and did not belong to the forest areas were defined as non-climate driven (NC), as there were few populations in the forest areas and the vegetation dynamics were mainly affected by climate factors.

\section{Results}

\subsection{NPP and NDVI Spatial Patterns and Interannual Variations}

The annual average NPP and NDVI from 2000 to 2015 were calculated based on the pixel-level statistics (Figure 2a,b). The variable spatial patterns of NPP and NDVI were consistent, with a gradual increase from upstream to downstream. The northwestern part of the basin was glacial land with no vegetation cover; thus, the NPP and NDVI values were equal to zero. Higher values (NPP $>200 \mathrm{gC} \mathrm{m}^{-2} \mathrm{yr}^{-1}$ or NDVI $>0.6$ ) were mainly located in the downstream. The interannual series of NPP has a steadily increasing trend over the past 16 years ranging from 102 to $128 \mathrm{gC} \mathrm{m}^{-2} \mathrm{yr}^{-1}$ in the whole basin $(p<0.05)$, with an average value of $122 \mathrm{gC} \mathrm{m}^{-2} \mathrm{yr}^{-1}$. The mean NDVI exhibited a significant increasing trend, varying between 0.417 and $0.489(p<0.05)$, with a mean value of 0.452 . Figure 2c,d depicts the spatial patterns of the changing trends in NPP and NDVI. During 2000-2015, approximately $74.73 \%$ of the river basin exhibited an advancing trend in NPP. The strongest advanced trends $\left(>2 \mathrm{gC} \mathrm{m}^{-2} \mathrm{yr}^{-1}\right)$ were detected mainly in the southeastern regions of downstream. Similarly, more areas increased in NDVI were detected, with $66.25 \%$ of the total pixels. The NPP in the northwest and river valley both experienced a severe declining trend, with magnitudes of changes less than $-1.00 \mathrm{gC} \mathrm{m}^{-2} \mathrm{yr}^{-1}$ and $-4.00 \mathrm{gC} \mathrm{m}^{-2} \mathrm{yr}^{-1}$, respectively. A significantly negative NDVI was also found in the northwest $(<-0.05 \mathrm{yr}-1)$ and river valley $\left(<-0.15 \mathrm{yr}^{-1}\right)$. Figure $2 \mathrm{e}, \mathrm{f}$ visually presents the qualitative classification of NPP trend and NDVI trend, whether those are increasing, decreasing, or unchanged. In general, vegetation degradation was relatively severe in the lower reaches of the basin. 


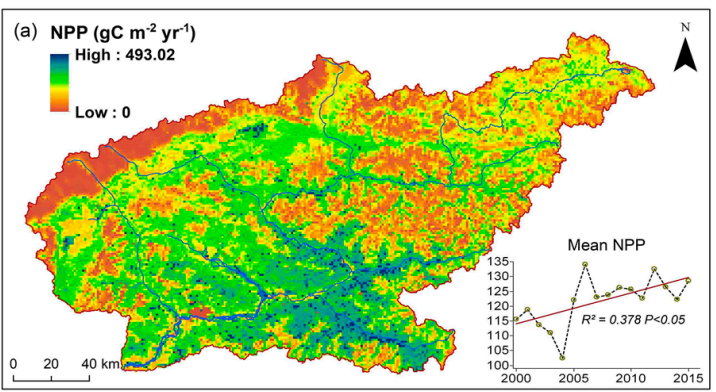

(a)

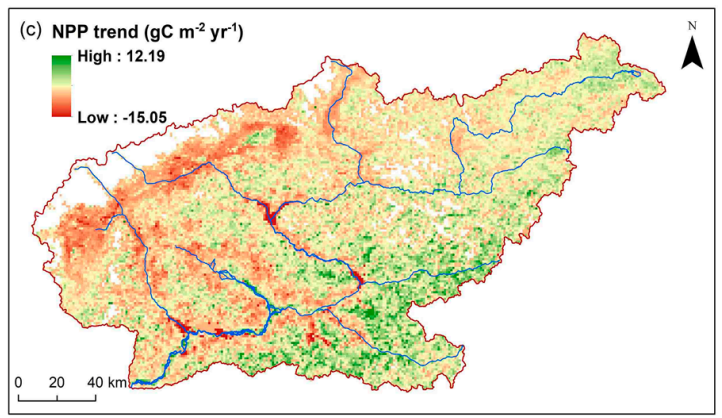

(c)

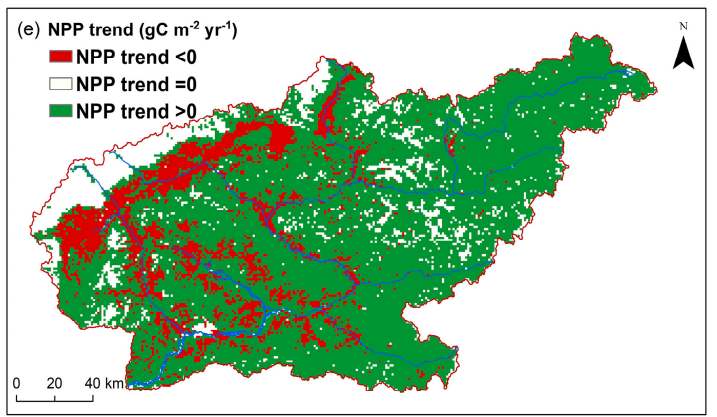

(e)

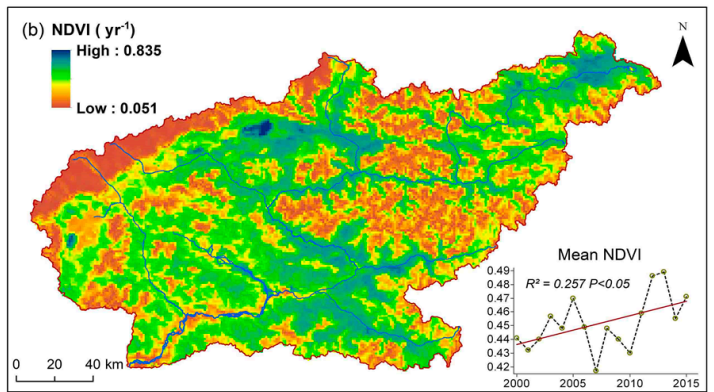

(b)

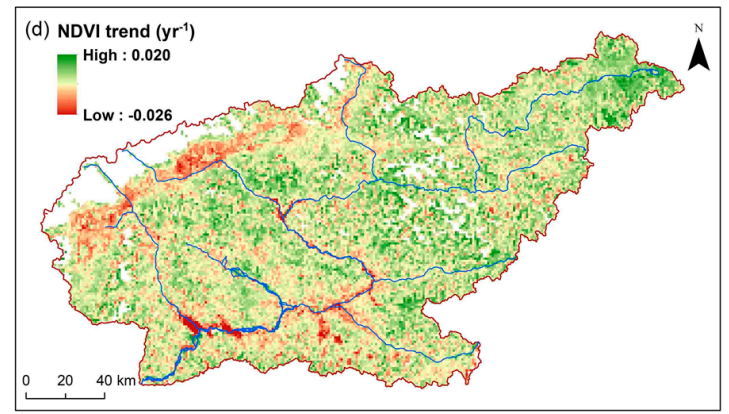

(d)

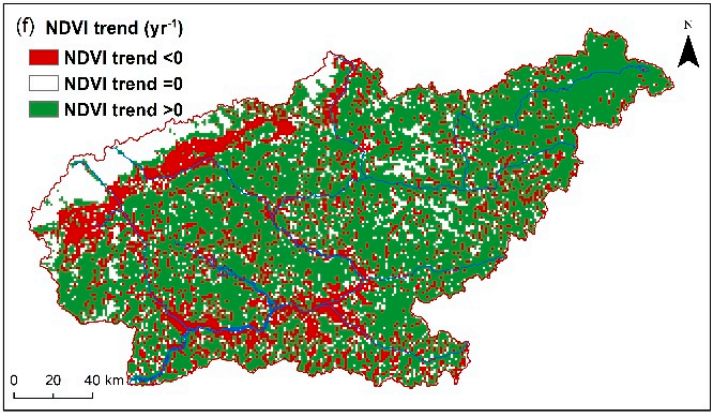

(f)

Figure 2. Spatial and temporal distributions of NPP, NDVI and their trends from 2000-2015: (a) annual mean NPP, (b) annual mean NDVI, the line charts indicate the annual variation in the spatially averaged values; (c) changing trend of NPP, (d) changing trend of NDVI, the white pixels represent the NOC areas; (e) qualitative classification of NPP trend, (f) qualitative classification of NDVI trend.

\subsection{Partition of Driving Factors for NPP and NDVI}

We firstly removed the NOC areas in all the pixels and then analyzed the partial correlations between NPP (NDVI) and precipitation $(\mathrm{P})$ and temperature $(\mathrm{T})$ in the remaining pixels to determine their contributions across different locations (Figure 3c-f). During 2000-2015, areas that experienced a significant negative partial correlation between NPP and P mainly occurred in the southeastern regions $(p<0.05)$, accounting for $20.94 \%$ of the entire Lhasa River Basin. Concurrently, approximately $3.85 \%$ of the total cells experienced a significant positive partial correlation between NPP and P $(p<0.05)$, mainly distributed in the northwestern regions and slightly distributed in river valleys. Most of the river basin areas experienced insignificant negative or positive partial correlations. Approximately $52.34 \%$ of the river basin showed a negative partial correlation between NDVI and P, especially in the southeastern regions ( $p<0.05$ ), accounting for $12.80 \%$ of the total area (Figure 3e). Meanwhile, strong positive partial correlations were observed in the northwest, in accordance with the results in NPP. Figure $3 \mathrm{~d}$, f present the results for spatial distribution of the partial correlation coefficient. Only $7.40 \%$ of pixels exhibited positive partial correlations between NPP and T were significant at $p<0.05$. Furthermore, almost no significant positive or negative partial correlation between NDVI and T was found in the whole river 
basin. To further determine the spatial relationship between NPP (NDVI) and P and T, the pixel-based multiple correlation coefficients were calculated from 2000-2015 (Figure 3g-h). Approximately 23.35\% of the total pixels showed a strong correlation between NPP and P and T $(p<0.05)$, indicating that the vegetation dynamics were mainly driven by climatic variables. Meanwhile, $13.20 \%$ of the areas showed a strong correlation between NDVI and climatic factors $(p<0.05)$. The areas driven by $\mathrm{P}$ and T variables occurred mainly in the southeastern and northwestern part of the watershed.

Figure $3 a, b$ presents the results for driving factors of annual vegetation dynamics based on the zoning criteria. During 2000-2015, the areas experiencing NPP dynamics driven by P accounted for $15.87 \%$ of the river basin, distributed in the southeast and northwest of high-altitude regions. Only $8.61 \%$ of the river basin showed the variation in NPP driven by T (4.15\%) or PT (4.46\%), dispersedly occurring in the northwestern regions. The changes in NPP in the remaining areas were mainly driven by NC, occupying $68.20 \%$ of the whole basin. The spatial distribution of the driving factors of NDVI were nearly consistent with the results in NPP. The variations in NDVI driven by climatic factors only occupied $16.19 \%$ of the river basin. The proportions of areas with NDVI changes driven by $\mathrm{T}(2.24 \%)$ or PT $(2.78 \%)$ were small across the river basin. The P had a more significant impact in the northwestern and southeastern parts, while the responses of vegetation growth to T and PT were scattered in some pixels. In about $70 \%$ of areas, vegetation growth was not controlled by climatic factors, indicating the more pronounced impacts of human disturbance. The vegetation dynamics induced by NC factors were located in the alpine meadow of the upper basin and the lower river valleys.

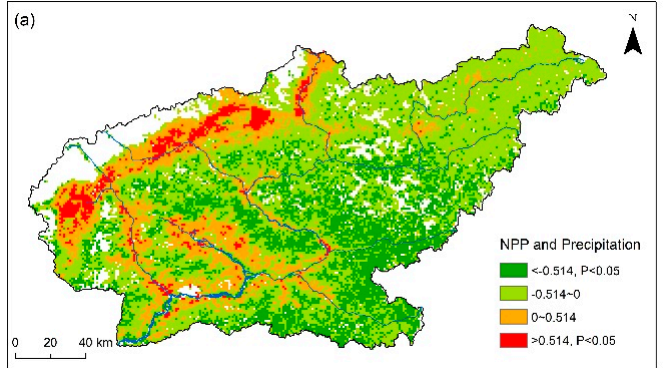

(a)

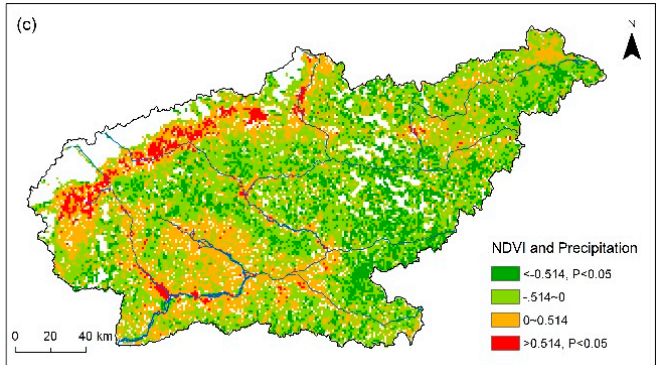

(c)

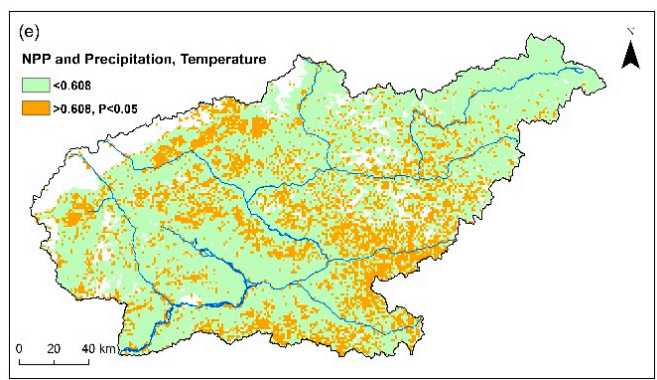

(e)

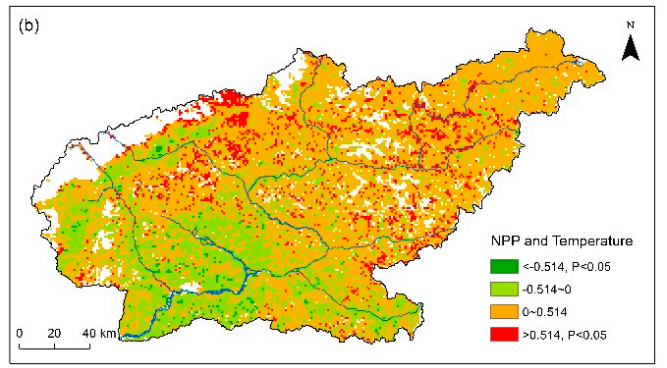

(b)

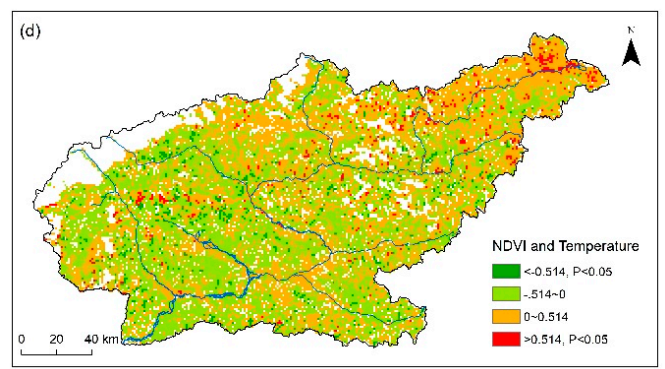

(d)

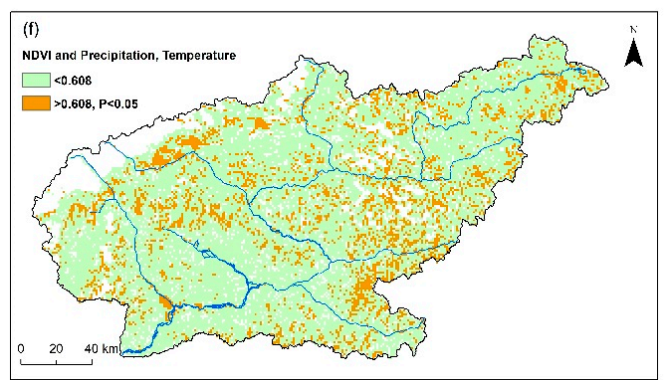

(f)

Figure 3. Cont. 


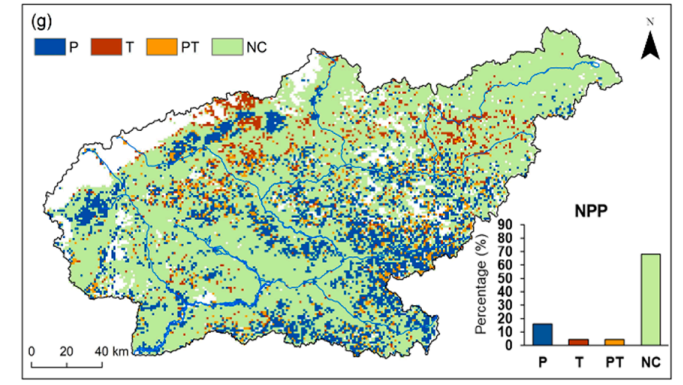

(g)

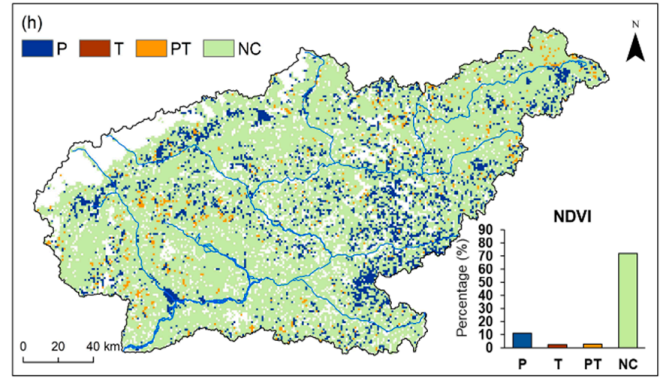

(h)

Figure 3. Driving factors of vegetation dynamics: (a) and (b) partial correlation coefficients between NPP and climatic variables; (c) and (d) partial correlation coefficients between NDVI and climatic variables; (e) and (f) multiple correlation coefficients between NPP (NDVI) and climatic variables; (g) and (h) the partitions for NPP and NDVI, the bar plots present the proportion of every driving factor.

\subsection{Relationships between Vegetation Dynamics and Human Activities in the Valleys}

According to the previous analysis, the vegetation dynamic on both sides of the lower river valley was mainly driven by NC, that is, the human disturbance was a primary factor. Due to the special topography, human activities such as urbanization, reservoir construction, and farmland practices were distributed along the river bank (Figure 1a,b). To identify the impacts of human activities on vegetation dynamics, we divided the Lhasa River (main stream and its tributaries) into five parts named R1, R2, $\ldots, \mathrm{R} 5$, and extracted the vegetation change trend at intervals of $1 \mathrm{~km}$ within the range of $10 \mathrm{~km}$ along each river (Figure 1a). Every $R_{x}$ unit represented a specific human activity. Among them, vegetation dynamics along R1 indicated the influence of reservoirs, since the cascade reservoirs were built on it. The impacts of urbanization on vegetation could be concluded based on analysis of R2 and R3, because these rivers run through the cities and towns. R4 and R5 represent the vegetation dynamics induced by farmland practices, as the farmland was distributed on both sides of these two rivers. These pixels were all selected from the NC areas in the neighborhood of specific human activity to indicate a single role for human activity. The vegetation change trends at different distances from the rivers were compared. We believe that if the trend value is the same at different distances from the river, it indicates that vegetation is hardly affected by human disturb; if the values increase with the distance, it means that human activities have a negative effect; otherwise, it is a positive effect.

Figure 4 presents the pixel-averaged change trend of NPP for every $1 \mathrm{~km}$ interval distance from the riverway. The vegetation growth along $\mathrm{R} 1$, the cascade reservoirs, and the parts between the reservoir groups showed the impacts of reservoir construction. In mountainous regions, reservoir construction often brings about large-scale physical disturbance, including cut and fill operations that destroy grasslands and croplands, and the construction of the cascade reservoir would also widen the river bank between two reservoirs and inundate the surrounding vegetation. Results showed the influence range of reservoir construction was within $6 \mathrm{~km}$ of the riverway. Due to the unique mountain and valley topography, the most intense reservoirs disturbance to vegetation growth was concentrated within a range of $1 \mathrm{~km}$, leading to a trend towards vegetation degradation. The results of the NPP trend along R2 and R3 presented the vegetation responses to urbanization. The NPP trend along R2 increased from 0.40 to $2.1 \mathrm{gC} \mathrm{m}^{-2} \mathrm{yr}^{-1}$ with no values less than zero. However, the change trend of $\mathrm{NPP}$ along R3 was from -0.80 to $0.50 \mathrm{gC} \mathrm{m}^{-2} \mathrm{yr}^{-1}$. At distances of no more than $3 \mathrm{~km}$, the vegetation was destroyed. Especially within the range of a $1 \mathrm{~km}$ distance, urbanization had a strong negative effect on vegetation growth, with a value of $-0.8 \mathrm{gC} \mathrm{m}^{-2} \mathrm{yr}^{-1}$. The gradient distribution of NPP along the R4 and $\mathrm{R} 5$ riversides showed the influence of the irrigated district construction on vegetation. The change trend in NPP along R4 decreased first and then increased with increasing distance from the riverway. The NPP decreased significantly from $1.20 \mathrm{gC} \mathrm{m}^{-2} \mathrm{yr}^{-1}$ at a distance of $1 \mathrm{~km}$ to $0.07 \mathrm{gC} \mathrm{m}^{-2} \mathrm{yr}^{-1}$ at a distance of $5 \mathrm{~km}$, and subsequently, the change trend of NPP began to increase beyond a $5 \mathrm{~km}$ 
distance. Similarly, the change trend of NPP away from the R5 bank was consistent with that from the R4 bank. The NPP trend decreased significantly from $1.20 \mathrm{gC} \mathrm{m}^{-2} \mathrm{yr}^{-1}$ at a distance of $1 \mathrm{~km}$ to $0.25 \mathrm{gC} \mathrm{m}^{-2} \mathrm{yr}^{-1}$ at a distance of $2 \mathrm{~km}$. As the distance increased to $10 \mathrm{~km}$, the change trend then increased to $1.20 \mathrm{gC} \mathrm{m}^{-2} \mathrm{yr}^{-1}$. The comparison of the change trend of NPP at different distances from the riverside showed two types of impacts. First, farming activities made a positive contribution to the growth of vegetation in a linear direction along the river. The irrigated districts were distributed along the main stream of the Lhasa River and Pengbo River due to restrictions of topography and water resources. Within a distance of $1 \mathrm{~km}$, fertilization and pesticide behaviors were conducive to the dry matter accumulation of crops and greatly promoted vegetation growth. Beyond a $1 \mathrm{~km}$ distance, the positive effect of human disturbance was gradually weakened, while the opposite negative effects began to emerge.

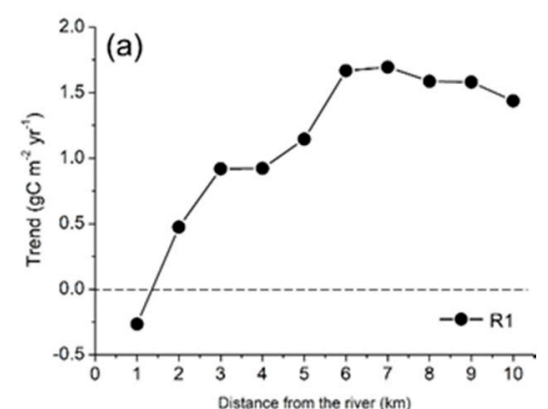

(a)

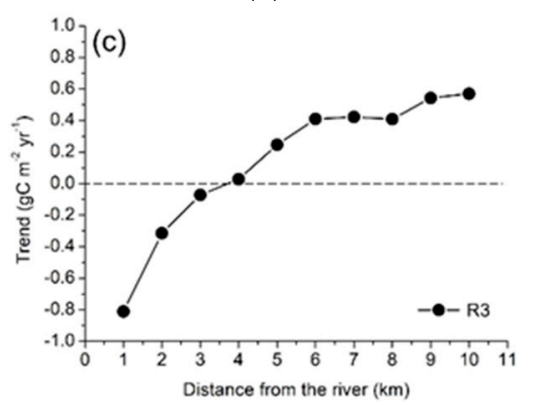

(c)

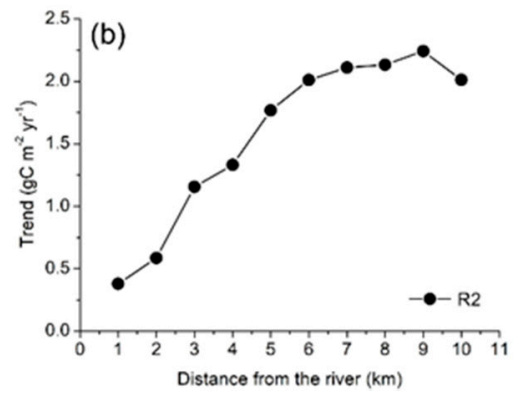

(b)

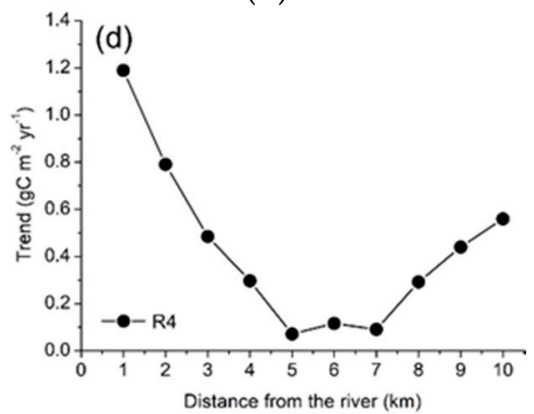

(d)

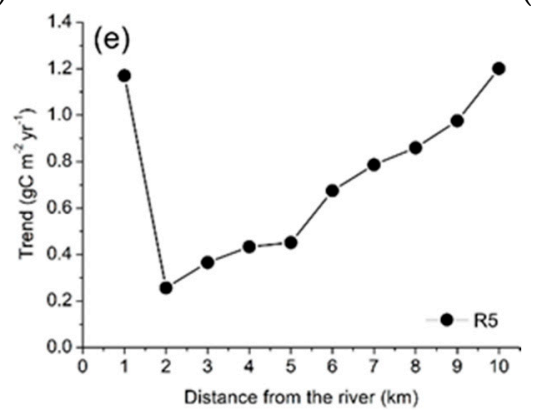

(e)

Figure 4. Comparison of the pixel-averaged change trend in NPP within a distance of 1-10 km away from the riverway: (a) R1; (b) R2; (c) R3; (d) R4; (e) R5.

The change trend in NDVI was compared for every $1 \mathrm{~km}$ interval from the river bank to explore the gradient distribution (Figure 5). In general, the pixel-average change trend of NDVI was consistent with that of NPP at different distances from the riverway, except along R4. In the R1 section between the reservoir groups, the influence range of cascade reservoirs was within a $6 \mathrm{~km}$ distance from the riverway, corresponding to the results of NPP. At a distance of $1 \mathrm{~km}$, cascade reservoirs had a damaging effect on vegetation, with a change trend of $-0.0022 \mathrm{yr}^{-1}$. The change trend in NDVI increased from 
$0.0012 \mathrm{yr}^{-1}$ at a distance of $2 \mathrm{~km}$ to $0.0030 \mathrm{yr}^{-1}$ at a distance of $6 \mathrm{~km}$, and subsequently, there was no significant difference beyond a $6 \mathrm{~km}$ distance. Urbanization at the expense of farmland destruction had a severe damaging effect on vegetation (R2) and was concentrated at a distance of $6 \mathrm{~km}$. The change trend in NDVI was less than zero due to human interference within $4 \mathrm{~km}$. The change trend (R3) was concentrated at a distance of $4 \mathrm{~km}$. The negative effect was greater within the range of $3 \mathrm{~km}$. The variation trend in NDVI along R4 at a distance of $1-5 \mathrm{~km}$ from the river was quite different from that of NPP. The change trend in NDVI presented a trend of continuous increase from -0.0020 to 0.0015 , while the change trend in NPP decreased at a distance of $1-5 \mathrm{~km}$ from the river. The main stream of the Lhasa River flowed through the center of Lhasa city, and there was also much nearby urbanization, some of which overlapped with the urbanization around R3. Land use conversion from cropland/grassland into urbanization was responsible for the decrease in NDVI, while agricultural activities could increase the carbon sequestration of crops in the irrigated districts, thus leading to an increase in NPP but a decrease in NDVI. However, the change trend in NDVI at a 1-10 km distance from the R5 bank corresponded to that of the results in NPP. The change trend in NDVI decreased from $0.0018 \mathrm{yr}^{-1}$ at a distance of $1 \mathrm{~km}$ to $0.0016 \mathrm{yr}^{-1}$ at a distance of $2 \mathrm{~km}$ and then increased to $0.0024 \mathrm{yr}^{-1}$ as the distance increased to $5 \mathrm{~km}$. The land use pattern near R5 was relatively singular, mainly farmlands in irrigated districts. Thus, the positive effect of agricultural activities was shown in the area within $1 \mathrm{~km}$ of the river.

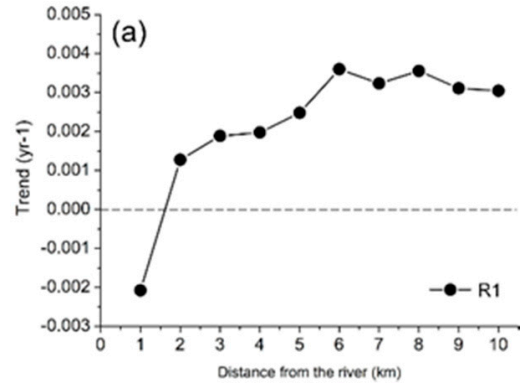

(a)

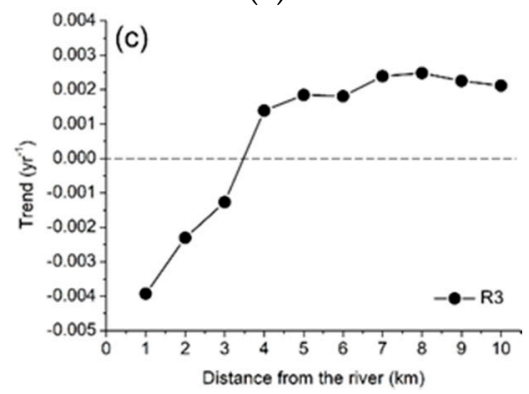

(c)

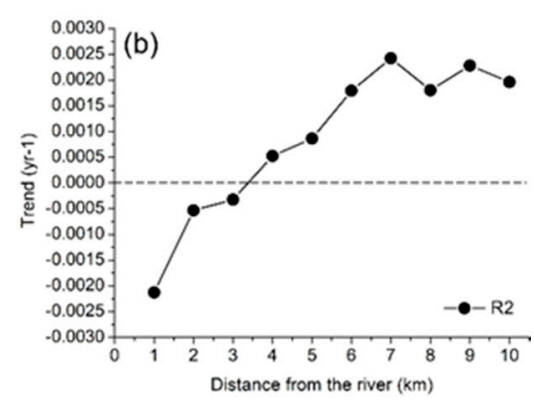

(b)

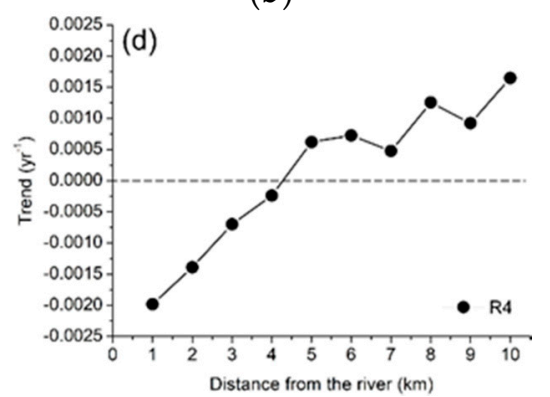

(d)

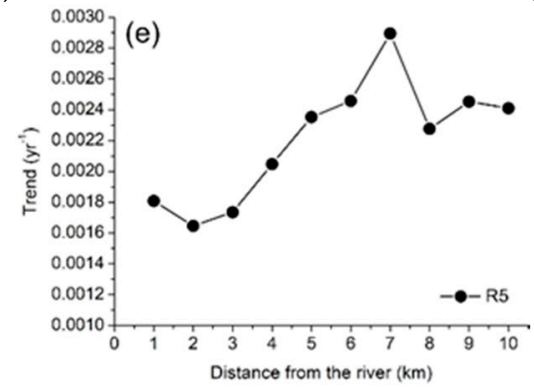

(e)

Figure 5. Comparison of the pixel-averaged change trend in NDVI within a distance of 1-10 km away from the riverway: (a) R1; (b) R2; (c) R3; (d) R4; (e) R5. 


\subsection{Relationships between Vegetation Dynamics and Human Activities at Different Altitude Levels}

Previous literature has confirmed that altitude plays a key role in vegetation growth because high altitudes are exposed to lower temperatures and unique physical conditions [43-45]. In the Lhasa River basin, however, the unique topography also determined the living habits of local people. High altitude also limited the scope of human activities and thus affected the distribution of population density. Zhao et al. (2017) pointed out that $99 \%$ of the population in Tibet was below $4500 \mathrm{~m}$ when exploring the relationship between population and terrain [46]. Combined with the results of Figure 6, the population density below $4500 \mathrm{~m}$ in this basin was primarily concentrated in the lower river valley, where vegetation dynamics were mainly driven by NC. Therefore, we further explored the vegetation response along the riverside to altitude with a dividing line of $4500 \mathrm{~m}$. Notably, those differences were mainly caused by various degrees of human activities across the altitude gradient. Figure 7 presented the differences in the change trend in vegetation growth at distances of $1 \mathrm{~km}, 4 \mathrm{~km}$, $7 \mathrm{~km}$, and $10 \mathrm{~km}$ from the riverway under an altitude gradient. The variation trend in NPP below $4500 \mathrm{~m}$ and above $4500 \mathrm{~m}$ along the river both increased with increasing distance from the riverway. The change trend in NPP above $4500 \mathrm{~m}$ increased from $1.05 \mathrm{gC} \mathrm{m}^{-2} \mathrm{yr}^{-1}$ at a distance of $1 \mathrm{~km}$ to $1.22 \mathrm{gC} \mathrm{m}^{-2} \mathrm{yr}^{-1}$ at a distance of $10 \mathrm{~km}$, while the change trend in NPP below $4500 \mathrm{~m}$ increased from $0.51 \mathrm{gC} \mathrm{m}^{-2} \mathrm{yr}^{-1}$ to $1.19 \mathrm{gC} \mathrm{m}^{-2} \mathrm{yr}^{-1}$. The differences between the change trend below and above $4500 \mathrm{~m}$ decreased significantly from $0.54 \mathrm{gC} \mathrm{m}^{-2} \mathrm{yr}^{-1}$ to $0.03 \mathrm{gC} \mathrm{m}^{-2} \mathrm{yr}^{-1}$. Especially within the range of $1-4 \mathrm{~km}$ along the river, the change trend above $4500 \mathrm{~m}$ was $0.50 \mathrm{gC} \mathrm{m}^{-2} \mathrm{yr}^{-1}$ higher than that below $4500 \mathrm{~m}$. No significant difference in the change trend in NDVI above $4500 \mathrm{~m}$ at a distance from $1 \mathrm{~km}$ to10 $\mathrm{km}$ alongside the river was detected, with a value of approximately $0.0030 \mathrm{yr}^{-1}$, while the change trend in NDVI below $4500 \mathrm{~m}$ increased from $-0.0012 \mathrm{yr}^{-1}$ to $0.0025 \mathrm{yr}^{-1}$. The differences caused by the altitudes decreased from $0.0041 \mathrm{yr}^{-1}$ to $0.0007 \mathrm{yr}^{-1}$, especially within the range of $1-4 \mathrm{~km}$, decreased sharply from $0.0041 \mathrm{yr}^{-1}$ to $0.0013 \mathrm{yr}^{-1}$, and then, the differences remained at approximately $0.0010 \mathrm{yr}^{-1}$ beyond a $4 \mathrm{~km}$ distance. This suggested that human activities hindered vegetation growth in areas within $4 \mathrm{~km}$ of the riverside below $4500 \mathrm{~m}$.

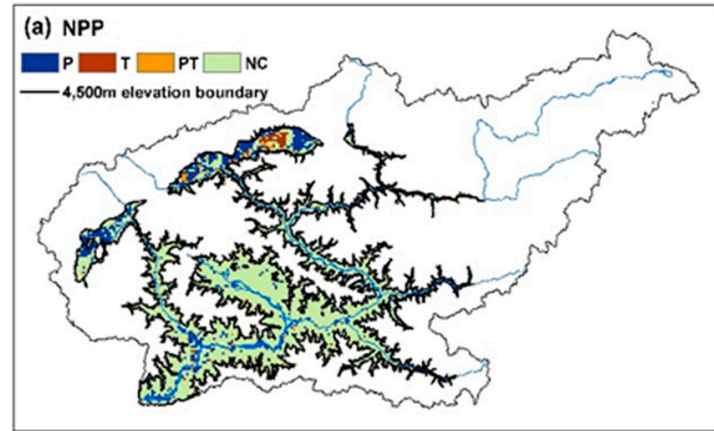

(a)

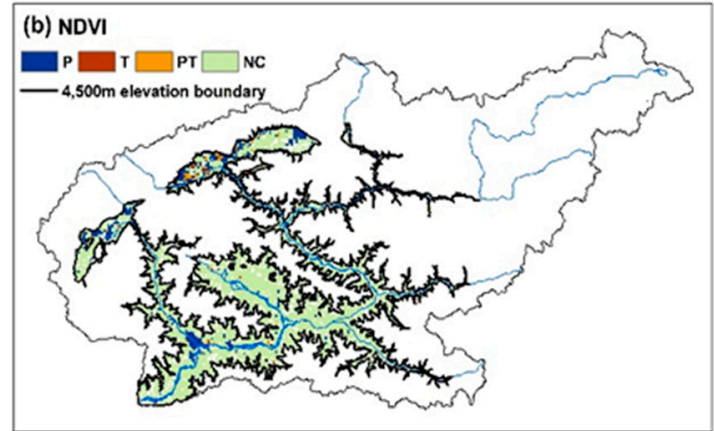

(b)

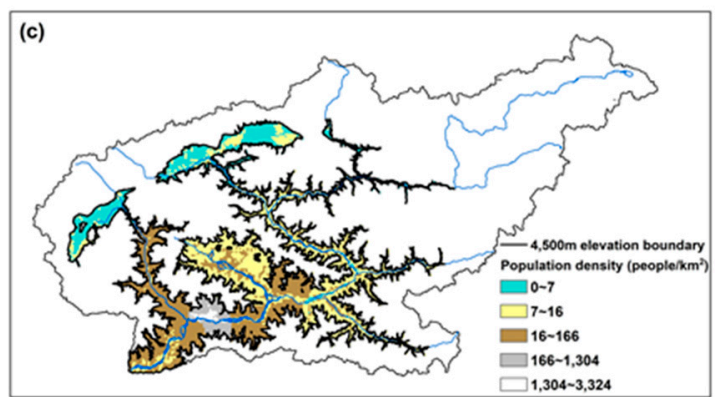

(c)

Figure 6. The vegetation dynamics driving factors: (a) driving factors of NPP; (b) driving factors of NDVI, and (c) population density below $4500 \mathrm{~m}$ in the Lhasa River Basin. 


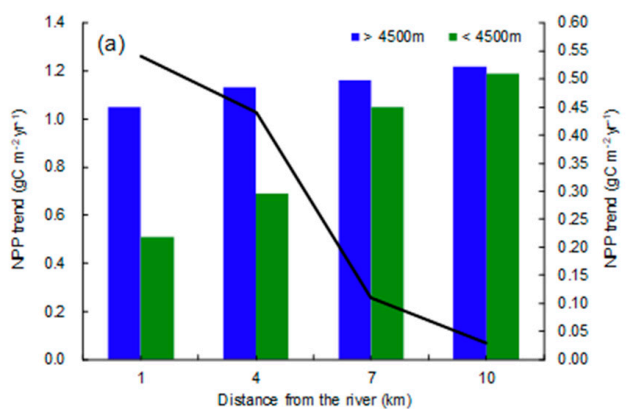

(a)

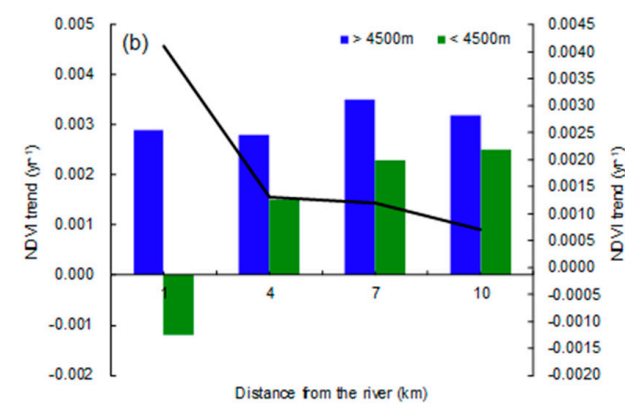

(b)

Figure 7. Comparison of vegetation variation trends at different distances from the riverway under altitude gradients: (a) NPP and (b) NDVI. Polyline represents the difference in variation trend (the right-side $\mathrm{Y}$ axis) caused by altitude level.

\subsection{Relationships between Vegetation Dynamics and Animal Husbandry}

As mentioned above, in the NC areas below $4500 \mathrm{~m}$ where is densely populated, the urbanization, reservoir, and farmland construction have extensive and profound impacts on vegetation growth. while human-induced grazing is a significant factor that cannot be ignored in the NC region over $4500 \mathrm{~m}$ such as in the northeastern basin. Grazing is a means of survival for herdsmen in the plateau. Different from captive breeding, the free-range livestock in the plateau depends primarily on natural pasture resources in the alpine meadows. In the NC areas above $4500 \mathrm{~m}$, the main land use type here is grassland (Figure 1b). Although there is almost no human footprint in these areas, the foraging behavior of livestock poses a great threat to the grassland vegetation. In order to determine the effect of grazing on vegetation growth, we collected the livestock number at the county-level in the whole basin for 16 years and further analyzed the correlation between the livestock number and vegetation dynamics in NC areas over $4500 \mathrm{~m}$. Figure 8 shows the correlation relationship between NPP or NDVI and sheep units at the county level in the whole basin during the period of 2000-2015. Results confirmed that vegetation growth was significantly negatively correlated with the livestock amounts, whereas vegetation growth decreased significantly with an increase in livestock number. The correlation coefficient between NPP and sheep units was -0.637 , with a significant negative correlation at the 0.001 significance level, and the coefficient between NDVI and sheep units was $-0.286(p<0.01)$. Both the NPP and NDVI appeared to linearly decrease when the sheep numbers increasing, with determination coefficients of -43.37 and 151.94 and of -0.034 and 0.480 , respectively. The $\mathrm{R}^{2}$ values were 0.405 at the 0.001 significance level and 0.082 at the 0.01 significance level. In contrast, animal husbandry had a more significant impact on the variation of NPP than those of NDVI. According to the above analysis, we can safely state that the livestock number posed a threat to vegetation growth, and human-induced grazing is suggested to the dominant factor of vegetation degradation in alpine meadows over $4500 \mathrm{~m}$.

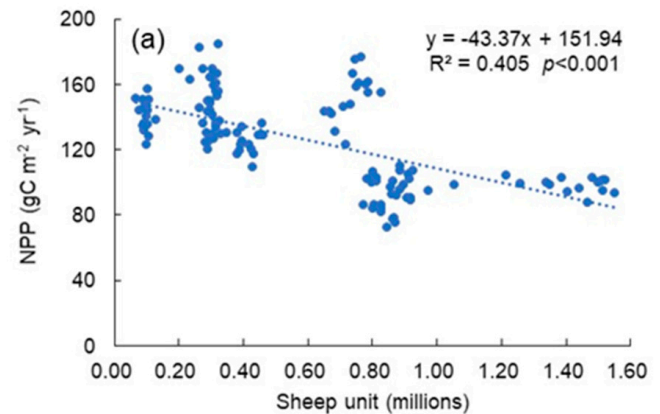

(a)

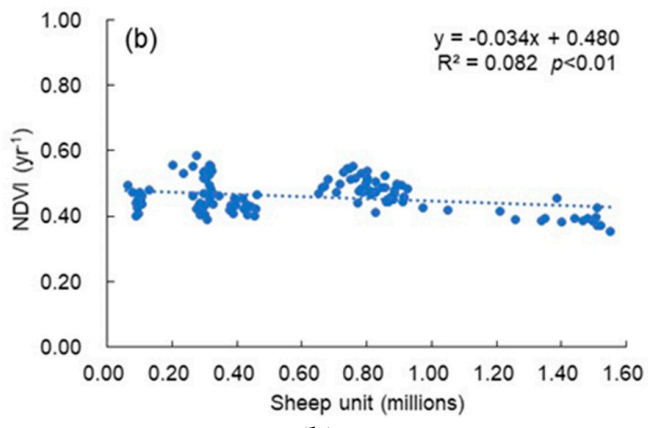

(b)

Figure 8. The correlation between the sheep unit and vegetation growth: (a) NPP and (b) NDVI. 


\section{Discussion}

Our findings showed the spatiotemporal dynamics of vegetation since the 21st century and its characteristics driven by climatic factors in the Lhasa River Basin. The spatial distribution of vegetation growth, as represented by NPP and NDVI, both showed obvious altitude heterogeneity, with higher values located in the lower altitude areas, which is similar to previous research [47]. Wang et al. (2017) also confirmed the negative relationship between vegetation productivity and the altitude gradient above $3500 \mathrm{~m}$ in the TP [43]. The overall trend in vegetation growth exhibited a significant advancing trend $(p<0.05)$ in recent decades despite grassland degradation in the northwest and human activity in the river valley, which has the consistency with previous studies [35,48].

Zhang et al. (2014) found climate conditions have driven long-term vegetation dynamics due to the low population density in the entire plateau [49]. In contrast, climate change did not bring significant changes in ecosystem structure in the Lhasa River Basin. In the whole Lhasa River Basin, only $24.48 \%$ and $16.19 \%$ of vegetation NPP and NDVI changes were driven by climatic factors in alpine vegetation, and the influence of $\mathrm{P}$ was much greater than that of $\mathrm{T}$ on vegetation growth. Although a warming climate is expected to help Northern Hemisphere green [50], some studies also showed that warming may not be the main driver of plateau grasslands [21,51,52]. Our analysis confirmed the findings from the study across the Lhasa River Basin by Han et al. (2018) [47]. In fact, the effects of climate conditions on the vegetation dynamics may be more complicated than we observed. Although the increased temperature can advance the phenological period of vegetation and increase the vegetation greenness, the acceleration of the transpiration of plants and soil water losses associated with rising temperatures may reduce the positive effects of temperature and exacerbate the demand for water. Thus, vegetation growth may be suppressed due to drought. There are other climatic driving factors affecting vegetation dynamics, such as radiation and wind, which can be taken into account in future studies.

Urbanization in the lower valley was proceeding rapidly to satisfy the needs of the whole society. Since the implementation of the national western development strategy, the urbanization rate of Lhasa reached more than $60 \%$ in 2015 [53]. The urbanization can alter the natural energy and material cycles of the ecosystem. is considered as one of the most disturbing processes from the view of ecology. [54]. Vegetation around the Duilong River (R3) was most seriously affected by urbanization since urban construction was mainly concentrated on both sides of the river downstream of this tributary. With a range of $1 \mathrm{~km}$ near the river, the vegetation showed a degradation trend, and the two vegetation indices NPP and NDVI were both less than zero. The massive land conversion from cropland to urbanization was responsible for such losses. Elmore et al. (2008) determined that land conversions have a greater effect on vegetation dynamics than climate conditions in China [55]. Similarly, Yu et al. (2009) also determined that urbanization in Shenzhen city has caused serious damage to regional vegetation dynamics, with an average annual carbon reduction of $45.93 \mathrm{Gg}$ [56]. The urbanization in the Lhasa River basin was weaker than that in other regions with rapid economic development, and its impact on vegetation was not at the same level of significance. However, a nonnegligible effect was seen on the plateau ecosystem, especially in the $3 \mathrm{~km}$ range along the river.

Infrastructure construction that accompanies regional policies such as reservoir group construction projects has a key role in existing natural ecosystems. Damming and other water reservoir construction activities may destroy the riparian vegetation zone. Wang et al. (2008) found that the impoundment of the Three Gorges Project inundated a large amount of vegetation coverage, and the area covered by vegetation in the upper reaches decreased by $3.31 \mathrm{~km}^{2}$ [57]. The construction of water conservancy projects led to drastic changes in natural vegetation in the reservoir area [58]. In the Lhasa River Basin, Zhikong-Pangduo reservoir group construction resulted in severe disturbance to the vegetation in the middle section of the reservoir groups. The impact range of reservoir construction on vegetation in the middle section was within $6 \mathrm{~km}$ of the river, and the damage to vegetation was the greatest within $1 \mathrm{~km}$. The two water reservoir construction projects at the cost of occupying the grassland were the main cause of vegetation degradation. Although the increased water collection areas may increase 
the moisture content in the air, which was conducive to surrounding vegetation growth, this land conversion from grassland into waters brought more direct damage to vegetation.

Intensive agricultural practices such as management measures and planting methods are an indispensable part of anthropogenic activities that influence vegetation productivity. In fact, fertilization and irrigation infrastructures are good indicators of soil quality and productivity due to their favorable effects on physical and chemical properties, thus making positive differences in vegetation growth. In the Lhasa River Basin, agricultural development that accompanied national policies (One River and Two Tributaries region) has impacted existing cropland ecosystems. Croplands in the Lhasa River Basin were distributed along both sides of the river, the main stream, (R4) and Pengbo River (R5). Figure 4 presents the change trend in vegetation NPP along R4 and R5, which both showed a decreasing trend within the 1-5 km range and 1-2 km range, respectively. The upward trend in NPP was greater when the vegetation was closer to the river bank. More importantly, the vegetation NPP had the same growth trend with a value of $1.2 \mathrm{gC} \mathrm{m}^{-2} \mathrm{yr}^{-1}$ within a $1 \mathrm{~km}$ distance of the two rivers. Intensive fertilization and guaranteed irrigation had significant positive effects on the accumulation of plant organic matter, although the effect on vegetation greenness was not obvious. Figure 9 depicts the change in irrigation area and the amount of fertilizer and pesticides used during 2000-2014 in Lhasa city (lack of data in 2015). The cultivated area in Lhasa city decreased from $3.80 \times 10^{4}$ ha in 2000 to $3.48 \times 10^{4}$ ha in 2014, while the irrigation area increased from $3.02 \times 10^{4}$ ha to $3.19 \times 10^{4}$ ha. The proportion of effective irrigated area had a steady upward trend from the initial $79.5 \%$ to the recent $91.7 \%$. The quantity of fertilizer used could be divided into two phases. During the first stage, the consumption of fertilizers increased from 6 to 10 thousand tons, and then, in 2009, the consumption reached an inflection point with the growth rate increasing to 1.89 thousand tons per year. The amount of fertilizers used nearly doubled in only five years. The consumption of pesticides also showed a significant upward trend and fluctuated greatly. Thus, these intensive agricultural management practices contributed extraordinarily to the accumulation of organic matter. Similarly, Li and Zhao (2013) found that the positive effect of anthropogenic activities on cropland was quite clear and that improvements in management measures increased cropland NPP [59]. Maria et al. (2016) also confirmed that fertilization loads correlate linearly with the actual NPP [60]. Thus, agricultural management measures in the Lhasa River Basin were beneficial to vegetation growth. Our perception of the effects of agricultural practices on vegetation dynamics was limited to the annual scale. It is necessary for us to further study cropland vegetation dynamics on a monthly scale, especially during the crop growth period.

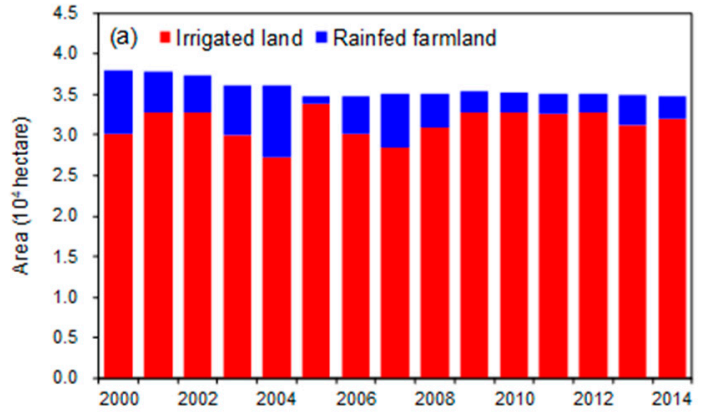

(a)

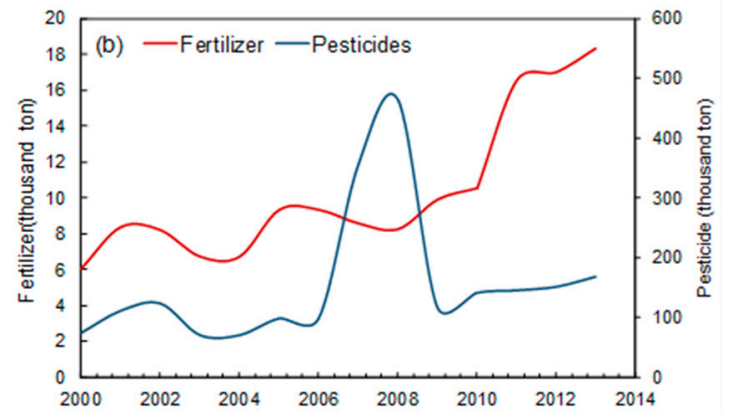

(b)

Figure 9. The variation trend in (a) irrigated land and (b) fertilizer and pesticides in Lhasa city from 2000 to 2014.

For thousands of years, the alpine meadow has been the most important pasture for Tibetan communities [61]. Grazing disturbance is generally recognized as the primary impetus for grassland degradation in the TP [62]. The inhabitants of the plateau region relied on grazing for livelihood and income. Due to the low education level of herdsmen, they may lack effective grazing methods and management measures [63]. Thus, vegetation degradation aggravated by overgrazing may be the most 
important reason [64]. In the NC areas over $4500 \mathrm{~m}$, grazing brings pressure on the grassland ecosystem. Our analysis confirmed a strong linear correlation between the livestock amounts and vegetation growth trend. The NPP and NDVI indices both showed a significant negative correlation with the number of livestock, especially the NPP at the 0.001 confidence level. The results had similarities with the findings by Feng et al. (2017) on the TP [27]. To address a series of pasture degradation problems, the national government has successively implemented ecological restoration projects such as the Grain for Green Program in 1999 and the Grazing Withdrawal Program in 2003. Xu et al. (2016) indicated that the relevant policy produced remarkable achievements on the restoration of alpine grasslands by controlling livestock numbers and decreasing grazing intensity [65]. In the ecologically fragile plateau region, balancing economic needs and ecological requirements remains an urgent issue.

Satellite-based techniques have become a common means to monitor vegetation dynamics. However, due to the spatiotemporal and ecological complexities in vegetation biochemical processes, some uncertainties in results still exist. In this paper, uncertainties related to datasets may be the main reason for the uncertainties in the results. The MOD17A3 NPP datasets widely used in monitoring natural ecological conditions still have uncertain factors due to meteorological inputs and cloud-contaminated FPAR/LAI [37]. There may be systematic errors and the filling of unreliable FPAR/LAI parameters in meteorological data, which are derived from assimilated datasets, and despite the improvement in the parameter accuracy, these values are still artificial and thus result in uncertainties [66]. Here, only one indicator was unable to scientifically determine the vegetation dynamics, and thus, integrated datasets and indicators were selected for better accuracy. The lack of historical ground-based observations also limited our ability to judge the accuracy of satellite-based products. In addition, the NPP and NDVI datasets are both deprived from MODIS products, while the spatial distribution maps of precipitation and temperature are from the products released by RESDC. Despite the same projection and resolution of data, perfect consistency is difficult to guarantee [67]. This problem is also inevitable in a combination of data with multiple data sources.

\section{Conclusions}

In this study, the spatiotemporal variations in vegetation NPP and NDVI were investigated in the Lhasa River Basin from 2000 to 2015, and further, the driving partition affecting the vegetation dynamics was defined. During the past 16 years, the variable spatial patterns of NPP and NDVI were consistent, with a gradual increase from upstream to downstream. The interannual series of NPP and NDVI both had a continuously increasing trend from 102 to $128 \mathrm{gC} \mathrm{m}^{-2} \mathrm{yr}^{-1}$ and from 0.417 to 0.489 $(p<0.05)$, with averages of $122 \mathrm{gC} \mathrm{m}^{-2} \mathrm{yr}^{-1}$ and 0.452 , respectively. The strongest advanced trends $\left(>2 \mathrm{gC} \mathrm{m}^{-2} \mathrm{yr}^{-1}\right.$ or $>0.005 \mathrm{yr}^{-1}$ ) were detected in mainly the southeastern and northeastern regions. There were no vegetation dynamics in about $10 \%$ of the basin. The vegetation dynamics driven by the climatic conditions accounted for only $20 \%$ of the whole area, distributed in the southeast and northwest, where precipitation was a more controlling climatic factor than temperature in terms of determining vegetation growth.

Accordingly, anthropogenic activities had a dominant role in vegetation dynamics. The construction of urbanization and reservoir led to vegetation degradation, but the farmland practices contributed the vegetation growth. The reservoir groups posed a threat to vegetation within a range of $6 \mathrm{~km}$, and the range of vegetation degradation is within $1 \mathrm{~km}$. Urbanization at the expense of croplands had an adverse impact on the vegetation within a $6 \mathrm{~km}$ distance from the surrounding river, and especially within a $3 \mathrm{~km}$ range, the vegetation degradation was serious. Intensive agricultural practices were beneficial for the cropland ecosystem within $5 \mathrm{~km}$ due to the increase in chemical fertilizers and pesticides, as well as the improvement in irrigation infrastructure, creating a positive effect on the accumulation of crop organic matter with an NPP trend value of $1.2 \mathrm{gC} \mathrm{m}^{-2} \mathrm{yr}^{-1}$. The highly intensive grazing activity exerted ecological environmental pressures, and there was a significant linear negative correlation between livestock numbers and vegetation coverage, which directly resulted in the decrease in grassland biomass and vegetation degradation. Our study 
quantitatively distinguished the extent to which climate factors and specific human activities affect vegetation growth at the watershed scale, although there is some uncertainty about the source of the datasets. The findings make an important contribution to the field of regional ecological environment management and sustainable development.

Author Contributions: Conceptualization, Y.L. and D.L.; data curation, D.L. and H.L.; writing—original draft preparation, D.L.; writing - review and editing, D.S., Y.C., and S.K.; supervision, Y.L.; funding acquisition, T.H. All authors have read and agreed to the published version of the manuscript.

Funding: This study was financially supported by the Strategic Priority Research Program of the Chinese Academy of Sciences (XDA2004030102), the National Natural Science Foundation of China (91647204) and Tibet Agricultural and Animal Husbandry College under the Flexible Talent Recruitment Program.

Conflicts of Interest: The authors declare no conflict of interest.

\section{References}

1. Godinez-Alvarez, H.; Herrick, J.E.; Mattocks, M.; Toledo, D.; Van Zee, J. Comparison of three vegetation monitoring methods: Their relative utility for ecological assessment and monitoring. Ecol. Indic. 2009, 9, 1001-1008. [CrossRef]

2. Peng, J.; Liu, Z.; Liu, Y.; Wu, J.; Han, Y. Trend analysis of vegetation dynamics in Qinghai-Tibet Plateau using Hurst Exponent. Ecol. Indic. 2012, 14, 28-39. [CrossRef]

3. $\mathrm{Hu}, \mathrm{J}$. On the population management in the process of new urbanization of Lhasa. J. Tibet Univ. 2014, 29, 29-33, (In Chinese with English Abstract).

4. Piao, S.; Fang, J.; He, J. Variations in vegetation net primary production in the Qinghai-Xizang Plateau, China, from 1982 to 1999. Clim. Chang. 2006, 74, 253-267. [CrossRef]

5. Esser, G. Sensitivity of global carbon pools and fluxes to human and potential climatic impacts. Tellus. $B$ 1987, 39B, 245-260. [CrossRef]

6. Haberl, H. Human appropriation of net primary production as an environmental indicator: Implications for sustainable development. Ambio 1997, 26, 143-146. [CrossRef]

7. Hao, L.; Pan, C.; Fang, D.; Zhang, X.; Zhou, D.; Liu, P.; Liu, Y.; Sun, G. Quantifying the effects of overgrazing on mountainous watershed vegetation dynamics under a changing climate. Sci. Total Environ. 2018, 639, 1408-1420. [CrossRef] [PubMed]

8. Neigh, C.S.R.; Tucker, C.J.; Townshend, J.R.G. North American vegetation dynamics observed with multi-resolution satellite data. Remote Sens. Environ. 2008, 112, 1749-1772. [CrossRef]

9. Pei, F.; Li, X.; Liu, X.; Wang, S.; He, Z. Assessing the differences in net primary productivity between pre- and post-urban land development in China. Agric. Forest. Meteorol. 2013, 171, 174-186. [CrossRef]

10. Pettorelli, N.; Vik, J.O.; Mysterud, A.; Gaillard, J.M.; Tucker, C.J.; Stenseth, N.C. Using the satellite-derived NDVI to assess ecological responses to environmental change. Trends Ecol. Evol. 2005, 20, 503-510. [CrossRef] [PubMed]

11. Phinn, S.R.; Stow, D.A.; Zedler, J.B. Monitoring wetland habitat restoration in southern California using airborne multispectral video data. Restor. Ecol. 1996, 4, 412-422. [CrossRef]

12. Yang, $\mathrm{H} . ; \mathrm{Mu}, \mathrm{S} . ; \mathrm{Li}, \mathrm{J}$. Effects of ecological restoration projects on land use and land cover change and its influences on territorial NPP in Xinjiang, China. Catena 2014, 115, 85-95. [CrossRef]

13. Fensholt, R.; Proud, S.R. Evaluation of Earth Observation based global long term vegetation trends-Comparing GIMMS and MODIS global NDVI time series. Remote Sens. Environ. 2012, 119, 131-147. [CrossRef]

14. Li, Z.; Chen, Y.; Wang, Y.; Fang, G. Dynamic changes in terrestrial net primary production and their effects on evapotranspiration. Hydrol. Earth Syst. Sci. 2016, 20, 2169-2178. [CrossRef]

15. Phillips, L.B.; Hansen, A.J.; Flather, C.H. Evaluating the species energy relationship with the newest measures of ecosystem energy: NDVI versus MODIS primary production. Remote Sens. Environ. 2008, 112, 3538-3549. [CrossRef]

16. Bao, G.; Qin, Z.; Bao, Y.; Zhou, Y.; Li, W.; Sanjjav, A. NDVI-Based Long-Term Vegetation Dynamics and Its Response to Climatic Change in the Mongolian Plateau. Remote Sens. 2014, 6, 8337-8358. [CrossRef]

17. Cui, L.; Du, H.; Shi, J.; Chen, Z.; Guo, W. Spatial and Temporal Pattern of Vegetation NPP and Its Relationship with Climate in the Southeastern China. Sci. Geogr. Sin. 2016, 36, 787-793. (In Chinese with English Abstract) 
18. Foody, G.M. Spatial nonstationarity and scale-dependency in the relationship between species richness and environmental determinants for the sub-Saharan endemic avifauna. Glob. Ecol. Biogeogr. 2004, 13, 315-320. [CrossRef]

19. Gao, Y.; Huang, J.; Li, S.; Li, S. Spatial pattern of non-stationarity and scale-dependent relationships between NDVI and climatic factors-A case study in Qinghai-Tibet Plateau, China. Ecol. Indic. 2012, 20, 170-176. [CrossRef]

20. Liu, Y.; Li, Y.; Li, S.; Motesharrei, S. Spatial and temporal patterns of global NDVI trends: Correlations with climate and human factors. Remote Sens. 2015, 7, 13233-13250. [CrossRef]

21. Luo, L.; Ma, W.; Zhuang, Y.; Zhang, Y.; Yi, S.; Xu, J.; Long, Y.; Ma, D.; Zhang, Z. The impacts of climate change and human activities on alpine vegetation and permafrost in the Qinghai-Tibet Engineering Corridor. Ecol. Indic. 2018, 93, 24-35. [CrossRef]

22. Mishra, N.B.; Mainali, K.P. Greening and browning of the Himalaya: Spatial patterns and the role of climatic change and human drivers. Sci. Total Environ. 2017, 587, 326-339. [CrossRef] [PubMed]

23. Liu, R.; Xiao, L.; Liu, Z.; Dai, J. Quantifying the relative impacts of climate and human activities on vegetation changes at the regional scale. Ecol. Indic. 2018, 93, 91-99. [CrossRef]

24. Mao, D.; Wang, Z.; Wu, B.; Zeng, Y.; Luo, L.; Zhang, B. Land degradation and restoration in the arid and semiarid zones of China: Quantified evidence and implications from satellites. Land Degrad. Dev. 2018, 29, 3841-3851. [CrossRef]

25. Feng, Q.; Ma, H.; Jiang, X.; Wang, X.; Cao, S. What Has Caused Desertification in China? Sci. Rep. 2015, 5, 15998. [CrossRef] [PubMed]

26. Zhang, Y.; Zhang, C.; Wang, Z.; Chen, Y.; Gang, C.; An, R.; Li, J. Vegetation dynamics and its driving forces from climate change and human activities in the Three-River Source Region, China from 1982 to 2012. Sci. Total Environ. 2016, 563, 210-220. [CrossRef] [PubMed]

27. Chen, F.; Wang, H.; Yuan, Y. Two centuries of temperature variation and volcanic forcing reconstructed for the northern Tibetan Plateau. Phys. Geogr. 2017, 38, 248-262. [CrossRef]

28. Gao, Q.; Guo, Y.; Xu, H.; Ganjurjav, H.; Li, Y.; Wan, Y.; Qin, X.; Ma, X.; Liu, S. Climate change and its impacts on vegetation distribution and net primary productivity of the alpine ecosystem in the Qinghai-Tibetan Plateau. Sci. Total Environ. 2016, 554, 34-41. [CrossRef] [PubMed]

29. Lu, H.; Huang, Q.; Zhu, J.; Zheng, T.; Yan, Y.; Wu, G. Ecosystem type and quality changes in Lhasa River Basin and their effects on ecosystem services. Acta Ecol. Sin. 2018, 38, 8911-8918. (In Chinese with English Abstract)

30. Yan, Y.; Zhao, C.; Quan, Y.; Lu, H.; Rong, Y.; Wu, G. Interrelations of ecosystem services and rural population wellbeing in an ecologically-fragile area in North China. Sustainability 2017, 9, 709. [CrossRef]

31. Alberti, M. The effects of urban patterns on ecosystem function. Int. Reg. Sci. Rev. 2005, 28, 168-192. [CrossRef]

32. Han, G.; Yang, Y.; Yan, S. Vegetation Activity Trend and Its Relationship with Climate Change in the Three Gorges Area, China. Adv. Meteorol. 2013, 2013, 235378. [CrossRef]

33. Sainju, U.M.; Singh, B.P.; Whitehead, W.F. Long-term effects of tillage, cover crops, and nitrogen fertilization on organic carbon and nitrogen concentrations in sandy loam soils in Georgia, USA. Soil. Till. Res. 2002, 63, 167-179. [CrossRef]

34. Mu, S.; Zhou, S.; Chen, Y.; Li, J.; Ju, W.; Odeh, I.O.A. Assessing the impact of restoration-induced land conversion and management alternatives on net primary productivity in Inner Mongolian grassland, China. Glob. Planet. Chang. 2013, 108, 29-41. [CrossRef]

35. Huang, K.; Zhang, Y.; Zhu, J.; Liu, Y.; Zu, J.; Zhang, J. The Influences of Climate Change and Human Activities on Vegetation Dynamics in the Qinghai-Tibet Plateau. Remote Sens. 2016, 8, 876. [CrossRef]

36. Running, S.W.; Nemani, R.R.; Heinsch, F.A.; Zhao, M.S.; Reeves, M.; Hashimoto, H. A continuous satellite-derived measure of global terrestrial primary production. BioScience 2004, 54, 547-560. [CrossRef]

37. Zhao, M.S.; Heinsch, F.A.; Nemani, R.R.; Running, S.W. Improvements of the MODIS terrestrial gross and net primary production global data set. Remote Sens. Environ. 2005, 95, 164-176. [CrossRef]

38. Zhao, M.; Running, S.W.; Nemani, R.R. Sensitivity of Moderate Resolution Imaging Spectroradiometer (MODIS) terrestrial primary production to the accuracy of meteorological reanalyses. J. Geophys. Res.-Biogeo. 2006, 111. [CrossRef]

39. Bandaru, V.; West, T.O.; Ricciuto, D.M.; Izaurralde, R.C. Estimating crop net primary production using national inventory data and modis-derived parameters. Isprs. J. Photogramm. 2013, 80, 61-71. [CrossRef] 
40. Zhang, X.; Susan Moran, M.; Zhao, X.; Liu, S.; Zhou, T.; Ponce-Campos, G.E.; Liu, F. Impact of prolonged drought on rainfall use efficiency using modis data across china in the early 21 st century. Remote Sens. Environ. 2014, 150, 188-197. [CrossRef]

41. Madani, N.; Kimball, J.S.; Ballantyne, A.P.; Affleck, D.L.R.; Van Bodegom, P.M.; Peich, P.B.; Kattge, J.; Sala, A.; Nazeri, M.; Jones, M.O.; et al. Future global productivity will be affected by plant trait response to climate. Sci. Rep. 2018, 8, 2870. [CrossRef] [PubMed]

42. Huete, A.; Didan, K.; Miura, T.; Rodriguez, E.P.; Gao, X.; Ferreira, L.G. Overview of the radiometric and biophysical performance of the MODIS vegetation indices. Remote Sens. Environ. 2002, 83, 195-213. [CrossRef]

43. Wang, S.; Zhang, B.; Yang, Q.; Chen, G.; Yang, B.; Lu, L.; Shen, M.; Peng, Y. Responses of net primary productivity to phenological dynamics in the Tibetan Plateau, China. Agric. Forest. Meteorol. 2017, 232, 235-246. [CrossRef]

44. Shimono, A.; Zhou, H.; Shen, H.; Hirota, M.; Ohtsuka, T.; Tang, Y. Patterns of plant diversity at high altitudes on the Qinghai-Tibetan Plateau. J. Plant. Ecol. 2010, 3, 1-7. [CrossRef]

45. Song, S.; Liu, X.; Bai, X.; Jiang, Y.; Zhang, X.; Yu, C. Impacts of Environmental Heterogeneity on Moss Diversity and Distribution of Didymodon (Pottiaceae) in Tibet, China. PLoS ONE 2015, 10, e0132346. [CrossRef] [PubMed]

46. Zhao, T.; Song, B.; Chen, Y.; Yan, H.; Xu, Z. Analysis of population distribution and its spatial relationship with terrain elements in the Yarlung Zangbo River, Nyangqu River and Lhasa River region, Tibet. J. Geo-Inf. Sci. 2017, 19, 225-237. [CrossRef]

47. Han, W.Y.; Zhang, C.; Zeng, Y. Spatio-temporal changes and driving factors in the net primary productivity of Lhasa River Basin from 2000 to 2015. Acta Ecol. Sin. 2018, 38, 126-137, (In Chinese with English Abstract).

48. Zhang, C.; Li, Q.; Shen, Y.; Zhou, N.; Wang, X.; Li, J.; Jia, W. Monitoring of aeolian desertification on the Qinghai-Tibet Plateau from the 1970s to 2015 using Landsat images. Sci. Total Environ. 2018, 619, 1648-1659. [CrossRef] [PubMed]

49. Zhang, L.; Guo, H.; Wang, C.; Ji, L.; Li, J.; Wang, K.; Dai, L. The long-term trends (1982-2006) in vegetation greenness of the alpine ecosystem in the Qinghai-Tibetan Plateau. Environ. Earth Sci. 2014, 72, 1827-1841. [CrossRef]

50. Tucker, C.J.; Slayback, D.A.; Pinzon, J.E.; Los, S.O.; Myneni, R.B.; Taylor, M.G. Higher northern latitude normalized difference vegetation index and growing season trends from 1982 to 1999. Int. J. Biometeorol. 2001, 45, 184-190. [CrossRef] [PubMed]

51. Wang, C.; Guo, H.; Zhang, L.; Liu, S.; Qiu, Y.; Sun, Z. Assessing phenological change and climatic control of alpine grasslands in the Tibetan Plateau with MODIS time series. Int. J. Biometeorol. 2015, 59, 11-23. [CrossRef] [PubMed]

52. Zhang, L.; Guo, H.; Ji, L.; Lei, L.; Wang, C.; Yan, D.; Li, B.; Li, J. Vegetation greenness trend (2000 to 2009) and the climate controls in the Qinghai-Tibetan Plateau. J. Appl. Remote Sens. 2013, 7, 3572. [CrossRef]

53. Hu, C.; Fu, B.; Liu, G.; Jin, T.; Guo, L. Vegetation patterns influence on soil microbial biomass and functional diversity in a hilly area of the Loess Plateau, China. J. Soil. Sediment. 2010, 10, 1082-1091. [CrossRef]

54. Pielke, R.A.; Walko, R.L.; Steyaert, L.T.; Vidale, P.L.; Liston, G.E.; Lyons, W.A.; Chase, T.N. The influence of anthropogenic landscape changes on weather in south Florida. Mon. Weather Rev. 1999, 127, 1663-1673. [CrossRef]

55. Elmore, A.J.; Shi, X.; Gorence, N.; Li, X.; Jin, H.; Wang, F.; Zhang, X. Spatial distribution of agricultural residue from rice for potential biofuel production in China. Biomass. Bioenerg. 2008, 32, 22-27. [CrossRef]

56. Yu, D.; Shao, H.; Shi, P.; Zhu, W.; Pan, Y. How does the conversion of land cover to urban use affect net primary productivity? A case study in Shenzhen city, China. Agric. Forest. Meteorol. 2009, 149, 2054-2060. [CrossRef]

57. Wang, J.; Xue, B.; Deng, X.; Wang, M. Research on Spatial and Temporal Changes of Riparian Vegetation Cover in the Three Gorges Dam Area Based on NDVI. Geo-Inf Sci. 2008, 10, 808-815. [CrossRef]

58. Zhao, X.; Zhou, W.Z.; Tian, L.; He, W.H.; Zhang, J.C.; Liu, D.H.; Yang, F. Effects of land-use changes on vegetation net primary productivity in the Three Gorges Reservoir Area of Chongqing. Acta Ecol. Sin. 2018, 38, 141-151, (In Chinese with English Abstract).

59. Li, C.H.; Zhao, J. Spatiotemporal variations of vegetation NPP and related driving factors in Shiyang River basin of Northwest China in 2000-2010. Chin. J. Ecol. 2013, 32, 712-718. (In Chinese with English Abstract) 
60. Maria, N.M.; Kastner, T.; Fetzel, T.; Haberl, H.; Kroisleitner, C.; Plutzar, C.; Erb, K.H. Mapping and analysing cropland use intensity from a NPP perspective. Environ. Res. Lett. 2016, 11, 014008. [CrossRef]

61. Klein, J.A.; Harte, J.; Zhao, X.Q. Experimental warming, not grazing, decreases rangeland quality on the Tibetan Plateau. Ecol. Appl. 2007, 17, 541-557. [CrossRef] [PubMed]

62. Lu, X.; Kelsey, K.C.; Yan, Y.; Sun, J.; Wang, X.; Cheng, G.; Neff, J.C. Effects of grazing on ecosystem structure and function of alpine grasslands in Qinghai-Tibetan Plateau: A synthesis. Ecosphere 2017, 8, e01656. [CrossRef]

63. Fang, Y. Managing the Three-Rivers Headwater Region, China: From Ecological Engineering to Social Engineering. Ambio 2013, 42, 566-576. [CrossRef] [PubMed]

64. Abahussain, A.A.; Abdu, A.S.; Al-Zubari, W.K.; El-Deen, N.A.; Abdul-Raheem, M. Desertification in the Arab Region: Analysis of current status and trends. J. Arid Environ. 2002, 51, 521-545. [CrossRef]

65. Xu, H.; Wang, X.; Zhang, X. Alpine grasslands response to climatic factors and anthropogenic activities on the Tibetan Plateau from 2000 to 2012. Ecol. Eng. 2016, 92, 251-259. [CrossRef]

66. Ren, H.; Zhou, G. Measuring the impacts of anthropogenic activities on Inner Mongolian temperate grassland. Land Degrad. Dev. 2018, 29, 2942-2950. [CrossRef]

67. Cai, H.; Yang, X.; Wang, K.; Xiao, L. Is Forest Restoration in the Southwest China Karst Promoted Mainly by Climate Change or Human-Induced Factors? Remote Sens. 2014, 6, 9895-9910. [CrossRef]

(C) 2020 by the authors. Licensee MDPI, Basel, Switzerland. This article is an open access article distributed under the terms and conditions of the Creative Commons Attribution (CC BY) license (http://creativecommons.org/licenses/by/4.0/). 